\title{
Risking the social bond: motivations to defend or to repair when dealing with displeasing information
}

\author{
Stine Torp Løkkeberg ${ }^{1}$ • Nicolay Gausel ${ }^{1} \cdot$ Roger Giner-Sorolla $^{2} \cdot$ Colin Wayne Leach $^{3,4}$
}

Accepted: 24 March 2021 / Published online: 12 April 2021

(C) The Author(s) 2021

\begin{abstract}
Our choice to withhold or disclose displeasing information to another can motivate concern about damage to our social bonds. In two experiments, using two different samples of university students in Norway, $(N=174$ and $N=217)$, we found that withholding unpleasant information led to greater concern for self- image and social-image than did disclosure. We also found that withholding elicited more shame, inferiority and rejection than disclosure, and in Experiment 2, withholding elicited more defensive motivation than disclosure. Consistent with our model, defensive motivation was mostly explained by concern for social-image, whereas relationship repair motivation was mostly explained by concern for self-image and felt shame. We discuss implications for the literature on shame and social bonds.
\end{abstract}

Keywords Displeasing $\cdot$ Withholding $\cdot$ Disclosing $\cdot$ Shame $\cdot$ Rejection $\cdot$ Repair $\cdot$ Defensiveness

Because social bonds are the means by which we fulfill the allimportant need to belong (Baumeister \& Leary, 1995) and to be socially accepted (Rogers, 1961), we are generally careful not to do things that endanger these bonds (Baumeister \& Leary, 1995; Gausel, 2013; Leach et al., 2015; Pardede et al., 2021; Scheff, 1994). However, sometimes we learn information that a close other will find displeasing, and we may wonder: Should we disclose it? After all, honesty is a moral virtue (Brambilla \& Leach, 2014). However, honesty might not always fare so well socially as it can be viewed as unkind (Levine \& Cohen, 2018) as the receiver can be

The two authors "Stine Torp Løkkeberg and Nicolay Gausel" contributed equally to this article.

Stine Torp Løkkeberg

stine.t.lokkeberg@hiof.no

1 Faculty of Health and Welfare, Østfold University College, Kobberslagerstredet 5, 1671, Kråkerøy, Norway

2 School of Psychology, University of Kent, Canterbury, UK

3 Departments of Psychology and Africana Studies, Barnard College, Columbia University, New York, NY, USA

4 Department of Psychology and Institute for Research in African American Studies, Faculty of Arts \& Sciences, Columbia University, New York, USA emotionally hurt by what we tell them (Jeffries \& Hornsey, 2012) and thus, "shoot the messenger" so to speak. Another possibility is therefore to withhold the information. However, withholding displeasing information may seriously backfire as the other person might learn of our omission, and view it as betrayal (e.g., Jeffries \& Hornsey, 2012; Levine \& Cohen, 2018; Ma et al., 2011). That is, withholding can increase the risk to be "shot" in the role of messenger if found out, making the dissolution of the social bond even more likely. Beyond social damage, withholding violates the pan-cultural moral virtue of honesty (Brambilla \& Leach, 2014; Leach et al., 2015). Thus, making the decision to withhold is likely to be more problematic than disclosure, because it leaves us with the self-critical realization that we have been immoral in addition to having failed socially (Weil et al., 1994).

The choice to disclose or to withhold displeasing information has serious implications for how we view ourselves and for our social bonds. Thus, in this research, we first examined the degree to which individuals appraised the decision to disclose or withhold as showing a defect in their moral self-image, or as damaging their social-image in the eyes of the other. We then tested how the self-critical feelings of shame, inferiority and rejection accompanying these appraisals can help explain which of two action motives prevails after having either disclosed or withheld: to defensively avoid the receiver of the displeasing information, or to approach and repair the relationship with the receiver. 


\section{Dealing with Threats to Morality and the Social Bond}

Both disclosing and withholding displeasing information can put one's social bonds at risk. Also, both decisions may be viewed as immoral, although withholding may be more so as it is dishonest in addition to being psychologically harmful. It is therefore important to examine how people appraise and feel about disclosing or withholding information displeasing to others. These reactions can help understand who is most likely to respond with defensive avoidance motivation as a self-centered protection of the relationship, and who is likely to respond with a more constructive other-centered wish to pro-socially repair the relationship.

Defensive Motivation Defensive motivation to run away, avoid, or cover-up may prevail when people have to communicate bad news. In contrast to a prevalent individualistic view of shame and related emotions in psychology that focuses on the defense of the individual self-image (e.g., Lewis, 1971; Tangney \& Dearing, 2002), but in line with more collectivistic and sociological thinking on shame Gausel and Leach (2011) argued that one's social-image in the eyes of others can also be defended. Consequently, they argued that social-image defense is caused by the subjectively appraised concern for condemnation and the subsequent subjective feeling of rejection, and that it is this appraisal-feeling chain that ignites the socially defensive motivations of avoidance and wanting to cover-up. In the context of risks to one's social bonds (potentially, either from making or avoiding painful disclosure), defensive motivation is the desire to avoid, minimize, conceal, or deny wrongdoing in order to hinder others from finding out about the immoral decision. Thus, socially defensive motivation is fueled by the fear that one's need for acceptance and belongingness may go unfulfilled if others discover and condemn one's immorality (Gausel, 2013).

In recent empirical support of this, Back et al. (2005) showed that health care professionals responded with avoidance motivations in order to avoid hurting the patient emotionally and thus act precautionary in order to avoid damage to the social bond with the patient. Similarly, Sparks et al. (2007) found that professional helpers tended to cover-up the seriousness of the displeasing information they had obtained by making it less clear or downplaying its importance for the patients in order to minimize their potential hurt feelings. Baile et al. (2000) found that the tendency to cover-up and lie about the seriousness of the displeasing information was motivated by a concern for being disliked and condemned for the information they carried (see also, Lezzoni et al., 2012). Finally, Gausel et al. (2016) showed that the more participants were associated with serious moral relationship failures, the more they were concerned about condemnation and felt rejected.
They demonstrated that the stronger this appraisal-feeling chain of concern for condemnation and feeling rejected, the more grew the motivation to cover-up their wrong-doing to hinder social scrutiny, and to physically avoid others who could find out about the immorality, and to psychologically avoid the immorality by trying to think of something else than their misdeed (see also Gausel et al., 2012).

Relationship Repair Motivation Threats to morality and the social bond, however, need not always be responded to defensively (Gausel \& Leach, 2011). Relationship repair motivation involves approaching the person harmed by the immorality in an apologetic and helpful spirit, working to repair damage to the relationship, and offering restitution and reform toward this end. According to Gausel and Leach (2011), one of the main underlying motivations behind such pro-social repair after moral failures, is the self-critical feeling of shame evoked by the concern that one suffers from a (reparable) defect in the self that has been revealed by the failure. That shame can promote pro-social repair motivations after failure is now well established (Berndsen \& Gausel, 2015; Berndsen \& McGarty, 2012; de Hooge et al., 2011; Gausel \& Brown, 2012; Gausel et al., 2016, 2018; Shepherd et al., 2013; Tangney et al., 2014; for a meta-analytic review, see Leach \& Cidam, 2015).

For instance, in a recent line of longitudinal research, Tangney and colleagues (2014) found that the more shame ex-convicts felt for their crime, the less recidivism was found; a clear, constructive outcome of shame. Somewhat similar to this, Lickel et al. (2014) found that recalled experiences of shame were associated with greater desire for future repair by wanting to reform the self (see also Gausel \& Brown, 2012; for a meta-analytic review, (see Leach \& Cidam, 2015). Moreover, Shepherd et al. (2013) found in their studies on illegitimate group behavior that the more shame felt, the more one would also speak up and take action against the immorality (see also Berndsen \& Gausel, 2015). Consequently, Berndsen and McGarty (2012) found that shame felt for immorality was a predictor of reparations to those hurt by the immorality. And finally, Gausel et al. (2016) found that the more shame felt for a moral failure, the stronger was the motivation for wanting to pro-socially communicate contrition and offer restitution to those hurt by the immorality (see also, Gausel et al., 2012). Pro-social repair in an apologetic and helpful spirit should therefore be an expected motivation after having put the bond 'at risk' with communicating information that can hurt and possibly harm the person. Through this pro-social, relationship repair approach, the social bond has a good chance of being mended despite the risk caused by the hurtful, displeasing information. The critical difference between pro-social repair and defensive behavioral responses appears to be prepared by the appraisal of self-image defect, as opposed to social-image defect, and motivated by feelings of shame rather than rejection. 


\section{The Current Studies}

In line with the model from Gausel and Leach (2011), the main purpose of the studies was thus to demonstrate how defensive motivation is mostly explained by concern for social-image, whereas relationship repair motivation is mostly explained by concern for self-image and felt shame, and how these two appraisal $\rightarrow$ feeling $\rightarrow$ motivation chains are affected by the decision to either withhold or disclose displeasing information. We hypothesized that if displeasing information was withheld, then people would experience higher levels of self-related appraisals (i.e., concern for one's self-image and concern for one's social-image), self-critical feelings (of shame, inferiority and rejection) and greater levels of motivation (to repair or to defend) than if it was disclosed. This is because of indications in the literature that, at least in most Western cultures, hiding potentially painful information is seen as more morally wrong than risking harm by being honest (e.g., Weil et al., 1994). Naturally, not all cultures share the same norm for communication in response to displeasing information. For instance, in more collectively oriented cultures medical professionals often share unpleasant information with the family but withhold it from the patient (Costantini et al., 2009; Muñoz Sastre et al., 2014; O'Sullivan, 2009; Salem et al., 2013). That said, we designed our studies to fit with the western, North-European culture in which the studies were conducted. ${ }^{1}$

Second, we hypothesized that defensive motivations would be explained by the concern for social-image (i.e., concern for condemnation) and the associated feelings of rejection and inferiority. In contrast, we hypothesized that pro-social relationship repair motivations would be explained by the appraisal of concern for a moral defect in one's self-image and the associated feeling of shame. Hence, by accounting for how people appraise and feel about themselves depending on their decision to withhold or disclose, we explain how, in the types of disclosure we studied, the strategy to disclose was the "less worse" situation for the communicator (and potentially for the receiver) Incidentally, we found this appraisal-emotionmotivation process to be more intense in closer social bonds (i.e., among friends, Study 2) than in more distant social bonds (i.e., with student colleagues, Study 1).

\section{Study 1}

In our first study, participants imagined they had learned displeasing information about the performance of a fellow

\footnotetext{
${ }^{1}$ While under some circumstances lies that benefit others are seen as moral (e.g., Levine \& Schweitzer, 2014), those studies presented lies that were clearly linked to material benefits for others. Situations such as the ones in our research, where disclosure might be emotionally painful but pragmatically helpful to the recipient, are less likely to yield positive views of dishonesty (Cantarero et al., 2019).
}

student (a more distant social bond), and in one condition that they had disclosed it to the student, while in another condition that they withheld it. As the literature on communication strategies suggest that 'toning down' information is an alternative communication strategy that combines aspects of disclosing and withholding (see Baxter, 1982; Brewin, 1991), we created a third, intermediate comparison condition in which participants imagined 'toning down' the displeasing information.

\section{Method}

\section{Participants and Procedure}

174 university students ( 62 men and 109 women; $\mathrm{M}_{\text {age }}=24$, range: 19-47 years) volunteered to participate anonymously. They were recruited in libraries and canteens at different universities in the southern part of Norway (ten additional participants who failed to report anything more than their demographics were excluded from the analyses).

All participants were asked to read the same scenario: "One of the students in your class calls you and asks if you could check the results on the exam because the student can't get online. When you check the results, you see that your classmate's grade is very poor, but the exam is passed". Following this, participants were randomly assigned to one of three conditions. ${ }^{2}$ In the 'disclose condition' $(N=61)$ participants read: "You decide to disclose to this student what you have found about his/her results on the exam". In the 'withhold condition' $(N=56)$ participants read: "You decide to withhold all you have found out". In the third 'toning down condition' $(N=$ 55) participants read: "You decide to omit specific information about the grade, and rather focus on the positive side of him/her having passed the exam".

Following this, participants responded to a standardized questionnaire containing all the dependent variables. All items were answered with a response scale that ranged from 1 (not at all) to 7 (very much). Upon completion of the study, each participant was debriefed.

\section{Measures}

Appraisals We measured concern for self-image and concern for social-image by adapting measures developed by Gausel et al. $(2012,2016)$ to the present context. Concern for

\footnotetext{
${ }^{2}$ We tried to manipulate exposure (your friend is going to explain to other people what you just told him/her) versus non-exposure (you are 100\% sure that your friend will keep this conversation confidential) in order to increase a concern for social-image. However, these attempts proved unsuccessful as there were no significant differences on wrongness in the 'disclose' condition, $\mathrm{F}(1,58)=2.87, p=.10$, partial $\mathrm{n} 2=.05$, in the 'toning down' condition, $\mathrm{F}(1$, $53)=0.17, p=.68$, partial $\eta 2=.00$ and in the 'withhold' condition $\mathrm{F}(1$, $52)=0.54, p=.47$, partial $\eta 2=.01$. This factor will not be examined further.
} 
(damaged) self-image ( $\alpha=.69)$ was measured with: "I think I have some moral failure because of what I said";" I think I am defective in some way because of what I said". Concern for (damaged) social-image $(\alpha=.84)$ was measured with: "Others can condemn me for what I said", "I think I could be isolated from others because of this situation".

Shame and Related Feelings We measured shame $(\alpha=.96)$, using three items found in many published measures of shame (e.g., Gausel \& Brown, 2012; Gausel et al., 2012, 2016; Iyer et al., 2007; Lickel et al., 2005; Tangney et al., 1996): "I feel disgraced when thinking about what I said", I feel humiliated when I think about what I said", and "I feel ashamed when thinking about what I said". We measured inferiority $(\alpha=84)$ with two items adapted from Gausel et al. (2012, 2016): "I feel inferior when thinking about what I said" and "I feel vulnerable when I think about what I said". The feeling of rejection $(\alpha=.88)$ was measured with three items adapted from Gausel et al. (2012, 2016): "I feel rejected when I think about what I said", "I feel alone when I think about what I said", and "I feel rebuffed when thinking about what I said".

Motivations We measured 'defensive motivation' using two scales adopted from Gausel et al. (2012, 2016; Gausel \& Brown, 2012). Avoidance ( $\alpha=.78)$ was measured using three items: "If I could I would like to avoid the student that called me", "I would rather not get mixed up in discussions about what I said", "If I were to encounter the student that called me, I would control my thoughts and think of something else than what I said". The motivation to cover-up $(\alpha=.83)$ the information was measured with five items: "I think I will make it less clear to others what I said", "I think I will be cautious sharing this information with others", "I will make the impact of this story less important to others", "I think I will selfcensor myself on this issue", "I will encourage people to focus on the other side of the story".

'Pro-social relationship repair motivation' was measured with two scales: motivation to repair the relationship, and acknowledgment of having harmed the other so that the repair motivation can be viewed as sincere (Gausel et al., 2012) instead of hypocritical (Batson et al., 1999). The motivation to repair the relationship was adapted from Gausel et al. (2012, $2016)$ using three items $(\alpha=.92)$ :" I will try to repair some of the damage I have caused", "I feel I should compensate to the student that called me for what I said", and "I feel I should reestablish the relationship between me and the student that called me". The acknowledgment of having hurt the other was developed especially for this study $(\alpha=.84)$ using two items: "I think the student that called me will be hurt by what I said" and "I think the student that called me will not be happy at what I said".

\section{Results}

\section{Experimental Effects}

Table 1 reports means, standard deviations and Cohen's $\mathrm{d}$ for all measures by experimental condition.

Appraisals A Multivariate Analysis of Variance (MANOVA) showed an overall, significant effect of the manipulation on participants' appraisals, $F(2,164)=11.45, p<.001$, partial $\eta 2=.123$. There was a significant univariate effect on concern for social-image $F(2,164)=9.641, p=.001$, partial $\eta 2=.105$. Pairwise comparisons demonstrated that concern for socialimage was significantly higher $(p<.001)$ in the 'withhold' condition $(M=3.13, S D=1.63)$ than in the 'disclose' condition $(M=2.00, S D=1.21)$. The concern for social-image was marginally higher $(p=.077)$ in the 'withhold' condition than in the 'toning down' condition $(M=2.54, S D=1.22)$. There was no significant difference $(p=.115)$ in concern for socialimage between the 'toning down' condition and the 'disclose' condition.

There was a significant univariate effect on the appraisal of concern for self-image, $F(2,164)=8.945, p=.001$, partial $\eta 2=.098$. The pairwise comparison revealed that concern for self-image was significantly higher $(p<.001)$ in the 'withhold' condition $(M=2.59, S D=1.60)$ than in the 'disclose' condition $(M=1.58, S D=1.01)$, and concern for self-image was significantly higher $(p=.012)$ in the 'toning down' condition $(M=2.18, S D=1.17)$ than in the 'disclose' condition. However, there was no significant difference $(p=.298)$ between the 'withhold' condition and the 'toning down' condition on concern for self-image.

Feelings A MANOVA showed that there was a significant overall effect of the manipulation on feelings, $F(3,163)=$ $7.65, p<.001$, partial $\eta 2=.123$. In line with our hypothesis, there was a significant univariate effect on felt shame, $F(2$, $164)=10.14, p<.001$, partial $\eta 2=.110$. The pairwise comparison yielded that felt shame was significantly higher $(p<.001)$ in the 'withhold' condition $(M=2.77, S D=1.81)$ than in the 'disclose' condition $(M=1.64, S D=1.05)$. Felt shame was also significantly $(p=.007)$ higher in the 'withhold' condition than in the 'toning down' condition $(M=$ $1.96, S D=1.13)$. There was no significant difference ( $p=.628)$ on felt shame between the 'toning down' condition and the 'disclose' condition.

As expected, there was a significant univariate effect on felt inferiority, $F(2,164)=9.07, p<.001$, partial $\eta 2=.100$. The pairwise comparison showed that felt inferiority was significantly higher $(p<.001)$ in the 'withhold' condition $(M=2.60$, $S D=1.62)$ than in the 'disclose' condition $(M=1.60, S D=$ 1.58). Felt inferiority was also a significantly higher $(p=.014)$ in the 'withhold' condition than in the 'toning down' 
Table 1 Mean and standard deviations of appraisals and feelings Study 1

\begin{tabular}{|c|c|c|c|c|c|c|c|c|}
\hline & \multicolumn{2}{|c|}{ Withhold } & \multicolumn{2}{|c|}{ Toning down } & \multicolumn{2}{|c|}{ Disclose } & \multirow{2}{*}{$\begin{array}{l}\text { Cohen's d } \\
1 \mathrm{v} 3\end{array}$} & \multirow{2}{*}{$\begin{array}{l}\text { Cohen's d } \\
1 \mathrm{v} 2\end{array}$} \\
\hline & Mean & $\mathrm{SD}$ & Mean & $\mathrm{SD}$ & Mean & $\mathrm{SD}$ & & \\
\hline Social-image & $3.13 \mathrm{a}$ & 1.63 & $2.54 \mathrm{~b}$ & 1.22 & $2.00 \mathrm{~b}$ & 1.21 & .78 & .44 \\
\hline Self-image & $2.59 \mathrm{a}$ & 1.60 & $2.18 \mathrm{~b}$ & 1.17 & $1.58 \mathrm{~b}$ & 1.01 & .75 & .54 \\
\hline Shame & $2.77 \mathrm{a}$ & 1.81 & $1.96 \mathrm{a}$ & 1.13 & $1.64 b$ & 1.05 & .76 & .29 \\
\hline Inferiority & $2.60 \mathrm{a}$ & 1.62 & $1.90 \mathrm{a}$ & 1,04 & $1.60 \mathrm{~b}$ & 1.58 & .72 & .22 \\
\hline Rejection & $2.51 \mathrm{a}$ & 1.63 & $1.76 \mathrm{a}$ & .96 & $1.56 \mathrm{~b}$ & .93 & .70 & .21 \\
\hline Avoidance & $3.41 \mathrm{a}$ & 1.80 & $3.12 b$ & 1.41 & $2.51 b$ & 1.48 & .54 & .42 \\
\hline Cover-up & $3.63 \mathrm{a}$ & 1.89 & $3.42 \mathrm{a}$ & 1.34 & $3.30 \mathrm{a}$ & 1.63 & .18 & .08 \\
\hline Acknowledgment of hurt & $3.62 \mathrm{a}$ & 1.89 & $3.05 \mathrm{a}$ & 1.46 & $3.24 \mathrm{a}$ & 1.86 & .20 & .11 \\
\hline Repair relationship & $3.31 \mathrm{a}$ & 1.75 & $3.10 \mathrm{a}$ & 1.69 & $2.74 \mathrm{a}$ & 1.74 & .32 & .20 \\
\hline
\end{tabular}

Note $N=174$. Scale range $=$ not at all (1) to very much (7), a and b differ significantly from each other condition $(M=1.90, S D=1.04)$. There was no significant difference $(p=.654)$ on felt inferiority between the 'toning' down condition and the 'disclose' condition.

Also, as expected, there was a significant univariate effect on felt rejection, $F(2,164)=9.27, p<.001$, partial $\eta 2=.102$. The pairwise comparison demonstrated that felt rejection was significantly higher $(p<.001)$ in the 'withhold' condition $(M=2.51, S D=1.63)$ than in the 'disclose' condition $(M=$ $1.56, S D=.93)$. Felt rejection was also significantly higher $(p=.005)$ in the 'withhold' condition than in the 'toning down' condition $(M=1.76, S D=.96)$. There was no significant difference $(p=.100)$ on felt rejection between the 'toning down' condition and the 'disclose' condition.

Motivations A MANOVA showed a significant overall effect of the manipulation on motivations. $F(2,160)=5.833$, $p=.004$, partial $\eta^{2}=.068$.

There was a marginal univariate effect on avoidance, $F(2$, $160)=4.75, p=.01$, partial $\eta 2=.056$. The pairwise comparison yielded that avoidance was moderately higher $(p=.010)$ in the 'withhold' condition $(M=3.41, S D=1.80)$ than in the 'disclose' condition $(M=2.51, S D=1.48)$. There was no significant difference $(p=.121)$ between the 'toning down' condition $(M=3.12, S D=1.41)$ and the 'disclose' condition, and there was no significant difference $(\mathrm{p}=.100)$ between the 'withhold' condition and the 'toning down' condition.

Although the means went in the proposed direction, there was no significant univariate effect on the other motivations; cover-up, $F(2,160)=.58, p=.581$, partial $\eta 2=.007$, repair relationship, $F(2,160)=1.78, p=.216$, partial $\eta 2=.019$, or acknowledgment of having hurt the other, $F(2,160)=1.35$, $p=.261$, partial $\eta 2=.017$.

\section{Structural Equation Modelling}

A SEM using AMOS 23 with Maximum Likelihood Estimation was performed to further explain hypotheses about the effects of our main variables (Kline 2011) of appraisals and feelings on 'defensive' (see Fig. 1a) and 'pro-social' (see Fig. 1b) motivation. As there was no significant difference between the 'withhold' and the 'toning down' conditions on wrongness and only small differences on the two appraisals, we merged these two conditions and coded them with 1 (i.e., a 'withhold' approach), while the disclosure condition was coded with -1 . Table 2 provides and overview of intercorrelations and descriptive statistics. ${ }^{3}$

Explaining 'Defensive' Motivation Despite a significant chisquare, $\chi^{2}(10)=28.52, p<.001\left(\chi^{2} / d f=2.93\right)$, other fit indices indicated that our hypothesized model fit the data reasonably well, $I F I=.981, C F I=.980, R M S E A=.103$ (see Kenny et al., 2015). Reflecting the experimental results, the 'withhold' condition was a positive and significant predictor of both concern for social-image and self-image (See Fig. 1a). In turn, both concern for social-image and self-image was positive, significant predictors of felt rejection, felt inferiority and felt shame. In partial support of our hypothesis, concern for social-image was a significant predictor of defensive motivation but the predicted path from felt rejection to defensiveness was non-significant. As expected, felt inferiority and felt shame were both non-significant predictors of 'defensive' motivation.

Explaining 'Pro-Social' Relationship Repair Motivation We used $A M O S 23$ to test how a concern for self-image would positively predict shame and relationship repair motivation as hypothesized (see Fig. 1b). Despite a significant chi-square,

\footnotetext{
${ }_{3}^{3}$ We assessed multicollinearity with variance inflation factors (VIF). According to Cohen et al. (2003) the tolerance value should not be less than .20 and the VIF values not greater than 10 . When shame, inferiority and rejection were entered into single linear regression analysis using collinearity diagnostics, the tolerance values ranged from .21 to .46 and the VIF values ranged from 2.14 to 4.72 , suggesting that the items were not affected by multicollinearity.
} 
Table 2 Study 1 . Scale intercorrelations and descriptive statistics

\begin{tabular}{|c|c|c|c|c|c|c|c|c|c|c|}
\hline & Variable & 1 & 2 & 3 & 4 & 5 & 6 & 7 & 8 & 9 \\
\hline 1 & Social-image & - & & & & & & & & \\
\hline 2 & Self-image & .66 & - & & & & & & & \\
\hline 3 & Shame & .68 & .77 & - & & & & & & \\
\hline 4 & Inferiority & .63 & .68 & .89 & - & & & & & \\
\hline 5 & Rejection & .63 & .59 & .73 & .85 & - & & & & \\
\hline 6 & Avoidance & .53 & .57 & .56 & .53 & .53 & - & & & \\
\hline 7 & Cover-up & .42 & .45 & .50 & .55 & 48 & .66 & - & & \\
\hline 8 & Acknowledgment of hurt & .46 & .37 & .47 & .43 & .38 & 47 & .56 & - & \\
\hline \multirow[t]{4}{*}{9} & Repair relationship & .51 & .51 & .58 & .57 & .50 & .43 & .50 & .53 & - \\
\hline & Mean & 2.56 & 2.10 & 2.10 & 2.02 & 1.93 & 2.99 & 3.44 & 3.31 & 3.04 \\
\hline & SD & 1.47 & 1.33 & 1.44 & 1.33 & 1.27 & 1.59 & 1.62 & 1.75 & 1.78 \\
\hline & $\alpha$ & .84 & .69 & .96 & .84 & .88 & .78 & .83 & .84 & .92 \\
\hline
\end{tabular}

Note. $\mathrm{N}=174$. Response scale ranged from (not at all) 1 to (very much) 7 $\chi^{2}(11)=21.23, p=.031\left(\chi^{2} / d f=1.93\right)$ our hypothesized model fit the data well as underlined by several fit indices: $I F I=.989, C F I=.988, R M S E A=.073$ (see Kenny et al., 2015). In good support of our hypotheses, felt shame was the only significant predictor of 'repair' motivation. As expected, neither felt inferiority nor felt rejection were significant predictors of 'repair' motivation.

\section{Discussion}

As we expected, participants in the 'withhold' and 'toning down' conditions were more concerned about their selfimage and their social-image, and felt more shame, inferiority and rejection, than those in the 'disclose' condition. Apparently withholding information was experienced as more of an unpleasant experience, while disclosing was experienced as the 'least worst thing to do' for the communicator. In fact, it seemed that any kind of concealment of displeasing information was viewed as a greater threat to morality and the interpersonal relationship, compared to full disclosure. In absolute scores, for example, the wrongness of withholding and toning down was near the scale midpoint, while the wrongness of disclosure was in the lower quarter of the scale. Although withholding displeasing information significantly increased avoidance motivation, it had weaker effects on wanting to cover-up the decision, to repair the relationship and to acknowledge having hurt the other.

Looking at the 'defensive' structural model, a concern for social image best predicted the feeling of rejection, whereas a concern for self-image best predicted felt shame. Felt rejection played less of a role in avoidance motivation than expected as the concern for social-image crystalized itself as the main explanation behind the avoidance motivation. The structural 'pro-social' model offered support for the expected role of shame in predicting repair motivation. Withholding displeasing information led to concern for self-image and it was those individuals who felt more shame about this who expressed greater motivation to repair their relationship with person they had wronged in this way.

Overall, some important parts of the proposed model were verified, in particular the link between self-image, shame and repair. However, the corresponding path involving rejection was less clear, and was better described as a direct effect of social image. Allowing for these imperfections, however, the overall picture of defensiveness motivation as more related to social image, and relationship repair motivation as more related to self-image via shame, was upheld. The finding that withholding only led to increases in motivation to avoid, and not the others, may possibly be due to the relatively less consequential nature of withholding information about an exam, compared to other more important facts in life that could be withheld.

\section{Study 2}

In this second study, we decided to examine the experience of withholding and disclosing displeasing information to a close friend, rather than the more distant student friend in Experiment 1. This time, we asked participants to come up with a personal example of a situation involving displeasing information, rather than using a fixed one. As moral acts are more consequential in the context of a close relationship and in terms of the participant's own example of displeasing information, these procedural improvements should make the situational experience become more vivid (see Clark \& Brisette, 2000). This should in turn lead to greater differentiation of the constructs assessed. In particular, we expected the different levels of social and self-image threat to be more 
consequential on all kinds of action motivation with a more vivid context.

Our hypotheses for Study 2 were Study 1's findings: 'withholders' should report stronger self-critical appraisals (i.e., concern for self-image and concern for social-image), selfcritical feelings (of shame, inferiority and rejection) and reactive motivations (defensiveness, relationship repair) than disclosers of displeasing information. The greater moral failure of withholding should explain increased motivations via the already described model of Gausel and Leach (2011) where the concern for social image $\rightarrow$ felt rejection pathway should predict defensive motivation, while the concern for self-image $\rightarrow$ felt shame pathway should predict repair relationship motivation,

It turned out that the third 'toning down' alternative that we opened up for in Study 1 appeared to be not so much an intermediate step between 'withholding' and 'disclosing' (see Baxter, 1982; Brewin, 1991) but more akin to 'withholding'. After all, in retrospect, withholding by toning down is still falls short of being open and honest. Therefore, in Study 2 , we omitted the toning-down condition to better focus on the more disparate strategies of completely withholding versus disclosing displeasing information.

\section{Method}

\section{Participants and Procedure}

Two hundred and seventeen university students (65 men, 152 women, Mage: 23, range: 18-46 years) were approached in libraries and canteens at different universities in the southern part of Norway and volunteered to participate without receiving compensation (nine additional participants failed to report anything more than their demographics and were thus excluded from the analyses).

In the first part of the questionnaire, participants were asked the following: "Please think of a specific person that is your friend. Imagine that you find out something displeasing that is relevant to your friend. You know that your friend will be very upset when he/she gets to hear it." In the 'disclose' condition, about half of the participants $(N=108)$ continued reading "you decide to communicate to your friend what you have found out." In the 'withhold' condition, the other half $(N=$ 109), continued reading "you decide NOT to communicate to your friend what you have found out." Following this, participants were asked to write down exactly what they imagined. We wanted them to do this so we could be reassured that they had appraised the vignette in line with the questionnaire. In line with this, all participants understood instructions correctly, and most participants reported examples of cheating and medical problems. Participants were then presented with the standard questionnaire and asked to respond to all dependent variables using a response scale ranging from 1 (not at all) to 7 (very much).

\section{Measures}

All measures were identical to those in Study 1. Cronbach's alpha reliabilities were: Concern for self-image $(\alpha=.68)$, concern for social-image ( $\alpha=.92)$, felt shame $(\alpha=.93)$, felt inferiority $(\alpha=.77)$, felt rejection $(\alpha=.84)$, avoidance $(\alpha=.68)$, cover up $(\alpha=.71)$, wanting to repair the relationship $(\alpha=.79)$, acknowledgment of having hurt the other $(\alpha=.88)$.

\section{Results}

\section{Experimental Effects}

Appraisals A Multivariate Analysis of Variance (MANOVA) showed an overall effect of the manipulation on participant's appraisals, $F(2,214)=33.47, p<.001$, partial $\eta 2=.238$. As shown in Table 3, concern for self-image was significantly higher in the 'withhold' condition $(M=2.89, S D=1.52)$ than in the 'disclose' condition $(M=1.61, S D=.97), F(1,215)=$ $52.24, p<.001$, partial $\eta 2=.195$. In line with our hypothesis, the concern for social-image was also significantly higher in the 'withhold' condition $(M=4.52, S D=1.83)$ than in the 'disclose' condition $(M=2.80, S D=1.71), F(1,215)=51.07$, $p<.001$, partial $\eta 2=.192$.

Feelings A MANOVA showed an overall effect on participants' feelings, $F(3,213)=9.67, p<.001$, partial $\eta 2=.120$. There was a significant univariate effect on felt shame, $F(1,215)=28.93, p<.001$, partial $\eta 2=.119$, such that shame was significantly higher in the 'withhold' condition $(M=3.02$, $S D=1.73)$ than in the 'disclose' condition $(M=1.85, S D=$ 1.45). There was also a significant univariate effect on felt inferiority, $F(1,215)=27.79, p<.001$, partial $\eta 2=.059$, as participants in the 'withhold' condition expressed significantly higher inferiority $(M=2.59, S D=1.49)$ than did those in the 'disclose' condition $(M=1.89, S D=1.31)$. There was also a significant univariate effect on felt rejection, $F(1,215)=$ $12.73, p=.005$, partial $\eta 2=.036$, such the participants in the 'withhold' condition expressed significantly higher rejection $(M=2.33, S D=1.42)$ than did participants in the 'disclose' condition $(M=1.85, S D=1.05)$.

Motivations A MANOVA demonstrated an overall effect on the motivations, $F(4,207)=7.20, p<.001$, partial $\eta 2=.122$. There was a significant univariate effect on avoidance, $F(1$, $210)=12.03, p<.001$, partial $\mathrm{\eta} 2=.054$. As expected, participants in the 'withhold' condition expressed significantly greater avoidance $(M=3.35, S D=1.51)$ than in the 'disclose condition' $(M=2.66, S D=1.40)$. There was also a significant 


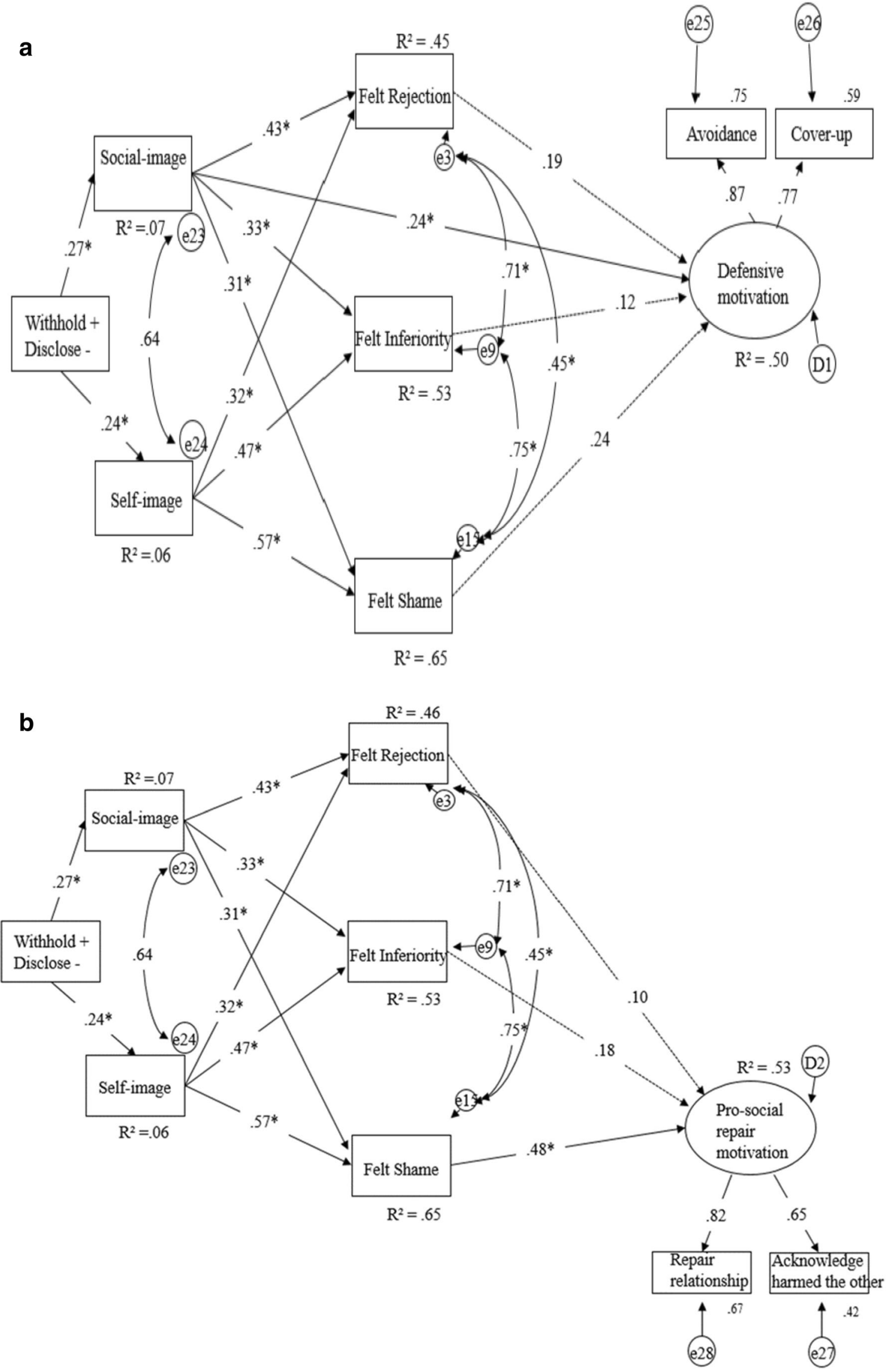


Fig. 1 a, Study 1. Structural model of the experimental effects on appraisals and feelings, and its relationship with the defensive motivations. Dashed lines $>.05$ and solid lines $<.05 \mathrm{~b}$, Study 1 . Structural model of the experimental effects on appraisals and feelings, and its relationship with repair motivations. Dashed lines $>.05$ and solid lines $<.05$

univariate effect on cover-up, $F(1,210)=15.36, p<.001$, partial $\eta 2=.068$, as participants in the 'withhold' condition expressed significantly cover-up $(M=4.32, S D=1.35)$ than in the 'disclose condition' $(M=3.61, S D=1.26)$.

There was a significant univariate effect on wanting to repair the relationship, $F(1,210)=14.33, p<.001$, partial $\eta 2=.064$, as participants in the 'withhold' condition expressed significantly higher wanting to repair the relationship $(M=4.34, S D=2.00)$ than did participants in the 'disclose' condition $(M=3.33, S D=1.92)$. We also found a significant univariate effect on acknowledgment of having hurt the other, $F(1,210)=18.77, p<.001$, partial $\eta 2=.082$. As hypothesized, participants in the 'withhold' condition expressed significantly higher acknowledgment $(M=4.92, S D=1.98)$ than in the 'disclose' condition $(M=$ $3.77, S D=1.85)$.

\section{Structural Equation Modelling}

As in Study 1, we used AMOS 23 to examine our predictions regarding the links between participants' appraisals, feelings, and motivations (see Fig. 2). See Table 4 for scale intercorrelations and descriptive statistics. ${ }^{4}$ We used a planned contrast where the 'disclose' condition was coded using -1 and the 'withhold' condition was coded with +1 . Despite a significant chi-square, $\chi^{2}(21)=66.974, \mathrm{p}<.001\left(\chi^{2} / \mathrm{df}=\right.$ $3.189)$, the hypothesized model fit the data adequately (Kenny et al., 2015): $I F I=.960, C F I=.959$, RMSEA $=.101$.

Similar to Study 1, the path from social image to defensiveness motivation was significant but did not appear to involve rejection, which was not significantly related to defensiveness. Again, the path from self-image to repair motivation involved shame, and the only significant cross-over between paths included a weaker prediction of shame by social- image (coefficient .22 as opposed to selfimage's .66). Inferiority, as before, was not associated with either kind of motivational outcome. These results were largely consistent with the model, with the same kinds of exceptions as found in Study 1, except that the paths now explained actual effects of the manipulation on cover-up, acknowledging harm, and repair.

\footnotetext{
$\overline{{ }^{4} \text { As in Study } 1}$, we tested multicollinearity among the feelings of shame, inferiority and rejection. The tolerance values ranged from .40 to .63 and the VIF values ranged from 1.57 to 2.48 , suggesting that the correlations were not affected by multicollinearity.
}

\section{Discussion}

Given the vividness of a personal example with a close friend, participants in the 'withhold' condition experienced significantly stronger appraisals (concern for self-image and concern for social-image) and self-critical feelings (of felt shame, felt inferiority and felt rejection) than did participants in the 'disclose' condition. Similarly, participants in the 'withhold' condition reported significantly higher repair relationship and defensive motivations than did participants in the 'disclose' condition.

The model again received general support with some deviations. Overall, paths from self-image concern to prosocial motivation and from social-image to defensive motivation were supported more strongly than vice versa, and the appraisal of concern for social-image was the strongest predictor of felt rejection. Also in support of our hypothesis, the appraisal of concern for self-image was the strongest predictor of felt shame, and felt shame predicted pro-social relationship repair motivation. However, the path from social-image to defensive motivation did not include rejection, and social-image had a significant relationship to shame (but less strongly than selfimage did). These deviations from the initially proposed model, however, are similar to those observed in Study 1.

\section{General Discussion}

Both disclosure and withholding of displeasing information can be problematic as either action can be seen as morally wrong and can put one's social bonds at risk. However, to better understand which of the two horns of this dilemma is experienced as worse for the holder of the information, we investigated the effects of disclosing and withholding displeasing information from the receiver across two kinds of social bonds: the more distant bond of student relationships and the more intimate one of close friendships.

We adapted the conceptual model of moral failure developed by Gausel and Leach (2011) to explain why and when people are coping through defensiveness motivation, and why and when people are coping through pro-social repair motivations when dealing with displeasing information.

\section{To Disclose or to Withhold Displeasing Information: What Is Worse?}

Participants in both studies reported being significantly more concerned about their self-image and their social-image in the eyes of others than participants in the disclosure conditions. These results confirm our hypotheses, and they validate previous theorizing on how people can appraise their failings (Gausel \& Leach, 2011; Gausel, 2013) as well as replicating recent research demonstrating that people typically appraise 
Table 3 Mean and standard deviations of appraisals and feelings Study 2

\begin{tabular}{lllllll}
\hline & \multicolumn{2}{l}{ Withhold } & & \multicolumn{2}{l}{ Disclose } & \multirow{2}{*}{ Cohen's d } \\
\cline { 2 - 3 } & Mean & SD & & Mean & SD & $1 v 2$ \\
\hline Social-image & $4.52 \mathrm{a}$ & 1.83 & $2.80 \mathrm{~b}$ & 1.71 & .97 \\
Self-image & $2.86 \mathrm{a}$ & 1.52 & $1.61 \mathrm{~b}$ & .97 & .98 \\
Shame & $3.02 \mathrm{a}$ & 1.73 & $1.85 \mathrm{~b}$ & 1.45 & .82 \\
Inferiority & $2.59 \mathrm{a}$ & 1.49 & $1.89 \mathrm{~b}$ & 1.31 & .49 \\
Rejection & $2.33 \mathrm{a}$ & 1.42 & $1.85 \mathrm{~b}$ & 1.05 & .38 \\
Avoidance & $3.35 \mathrm{a}$ & 1.51 & $2.66 \mathrm{~b}$ & 1.40 & .47 \\
Cover-up & $4.32 \mathrm{a}$ & 1.35 & $3.61 \mathrm{~b}$ & 1.26 & .54 \\
Acknowledgment of hurt & $4.92 \mathrm{a}$ & 1.98 & $3.77 \mathrm{~b}$ & 1.85 & .60 \\
Repair motivation & $4.34 \mathrm{a}$ & 2.00 & $3.33 \mathrm{~b}$ & 1.92 & .52 \\
\hline
\end{tabular}

Note. $N=217$. Scale range $=$ not at all (1) to very much (7), a and b is significant different from each other

more of a concern for their self-image and social-image the more serious their shortcomings are (Gausel et al., 2012, 2016).

In line with our hypotheses, withholding information led to a significantly increased concern for the self- and social-image and to a significant increase in shame-related feelings, in both studies, than compared to those who disclosed. These results support Clark and Brisette (2000) and they confirm contemporary theorizing on how people report feeling unpleasant emotions in situations where they appraise themselves negatively (Gausel \& Leach, 2011; Gausel, 2013). Moreover, the results from both studies go well with research on how selfrelevant failures promote feelings of shame (de Hooge et al., 2011; Gausel et al., 2012, 2016, 2018; Lewis, 1971; Lickel et al., 2014; Tangney et al., 2014), inferiority (Gausel et al., 2012, 2016) and rejection (Gausel et al., 2012, 2016).

In regard to motivation, withholding information led to more avoidant motivation in Study 1, and to an increase in all four subscales of defensive and repair motivation in Study 2. This may have been due to the more personally involving social bond. Consistent with Gausel and Leach (2011) the failures we commit, or are associated with, have the potential to motivate defensive strategies to minimize or hinder an exposure of the failure to others as in a 'damage control' strategy. That those who withheld more important information were more motivated to also acknowledge harm and to repair the relationship supported Gausel and Leach's (2011) arguments and findings (2012, 2016) that people can try to cope with their failures in a pro-social manner through admittance of wrongdoing and repair strategies - especially if they care for someone in their close bonds.

\section{Explaining Motivations}

The Social-Image $\rightarrow$ Defensiveness Pathway Although we had assumed that defensiveness motivation would be mediated through a feeling of rejection, we did not find significant support for this (even though it was a positive predictor). Instead, in both studies 'defensiveness motivation' was predicted directly by a concern for social-image. Albeit this did not completely conform to our expectations, it supports Gausel and Leach (2011) that a concern for social-image will elicit defensive motivations (Gausel et al., 2012, 2016, 2018). In fact, our model with a concern for social-image explained $50 \%$ of the variance of defensiveness in study 1 and $68 \%$ in Study 2, something that is considered unusually high for social sciences (Filho et al., 2011). Our results also fit nicely with Baile et al. (2000) findings in which their communicators of displeasing information tended to cover-up and lie about the seriousness of the displeasing information due to their concerns that others might dislike them. Defensiveness is thus likely to be motivated by fear that needs for acceptance and belongingness may go unfulfilled if others discover the immorality the self is associated with (see Gausel, 2013).

The Self-Image $\rightarrow$ Pro-Social Relationship Repair Pathway In support of our hypothesis, both studies demonstrated that a concern for self-image predicted felt shame, which in turn predicted pro-social relationship repair motivation. Our model with felt shame accounted for as much as $53 \%$ of the variance in Study 1 and 60\% in Study 2. Again, this level of variance explained is unusually high (Filho et al., 2011) and lines up with a recent meta-analysis by Leach and Cidam (2015) demonstrating that shame promotes pro-social relationship repair motivations when failure is seen as reparable. And it supports contemporary research showing that felt shame is a robust explanation of pro-social repair motivations on an individual level (e.g., de Hooge et al., 2011; Gausel et al., 2016; Tangney et al., 2014) as well as on a group level (Berndsen \& Gausel, 2015; Berndsen \& McGarty, 2012; Gausel \& Brown, 2012; Gausel et al., 2012, 2018; Shepherd et al., 2013). As such, felt shame based in concern for self-image seems to be functioning as a 'repairing bound trouble' motivator (Fearon 2004). Thus, shame has the potential to direct focus to a social bond in danger (Scheff, 1994) which can then be mended through an acknowledgment of having hurt the other and by taking pro-social steps to repair the social bond with the receiver (Gausel, 2013; Gausel \& Leach, 2011).

\section{Limitations}

Our studies have at least three possible limitations. First, some might say that vignette studies may not directly compare with studies using natural settings. While we appreciate such thoughts, it is important to see that our studies are a part of a program where we combine different literatures to better understand and explain communication of displeasing information. As such, it was important for us to gain the highest degree of uniformity and control over the stimuli situation 
Table 4 Study 2. Scale intercorrelations and descriptive statistics

\begin{tabular}{|c|c|c|c|c|c|c|c|c|c|c|}
\hline & Variable & 1 & 2 & 3 & 4 & 5 & 6 & 7 & 8 & 9 \\
\hline 1 & Self-image & - & & & & & & & & \\
\hline 2 & Social-image & .63 & - & & & & & & & \\
\hline 3 & Shame & .80 & .63 & - & & & & & & \\
\hline 4 & Inferiority & .67 & .58 & .77 & - & & & & & \\
\hline 5 & Rejection & .52 & .57 & .60 & .70 & - & & & & \\
\hline 6 & Avoidance & .48 & .56 & .51 & .52 & .45 & - & & & \\
\hline 7 & Cover-up & .39 & .40 & .40 & .37 & .36 & .41 & - & & \\
\hline 8 & Acknowledgment of hurt & .48 & .59 & .53 & .47 & .41 & .41 & .37 & - & \\
\hline \multirow[t]{4}{*}{9} & Repair relationship & .54 & .45 & .55 & .52 & .43 & .27 & .41 & .52 & - \\
\hline & Mean & 3.67 & 2.24 & 2.44 & 2.24 & 2.00 & 3.00 & 3.97 & 4.35 & 3.83 \\
\hline & SD & 1.97 & 1.48 & 1.70 & 1.44 & 1.37 & 1.50 & 1.34 & 1.99 & 2.02 \\
\hline & $\alpha$ & .92 & .68 & .93 & .77 & .84 & .68 & .71 & .88 & .79 \\
\hline
\end{tabular}

Note. $\mathrm{N}=217$. Response scale ranged from (not at all) 1 to (very much) 7 through a vignette design (Alexander \& Becker 1978). Moreover, Robinson and Clore (2001) conducted a study to find if there were any validity differences between vignette and realistic experiment conditions. They found a strong degree of correspondence in the reports, both in mean levels and in the pattern of appraisal-emotion relations and therefore concluded that "vignette methodologies can play a useful role in theory construction" (p. 1520).

Second, we measured shame related feelings using verbalized measurement tools. We know from former research that

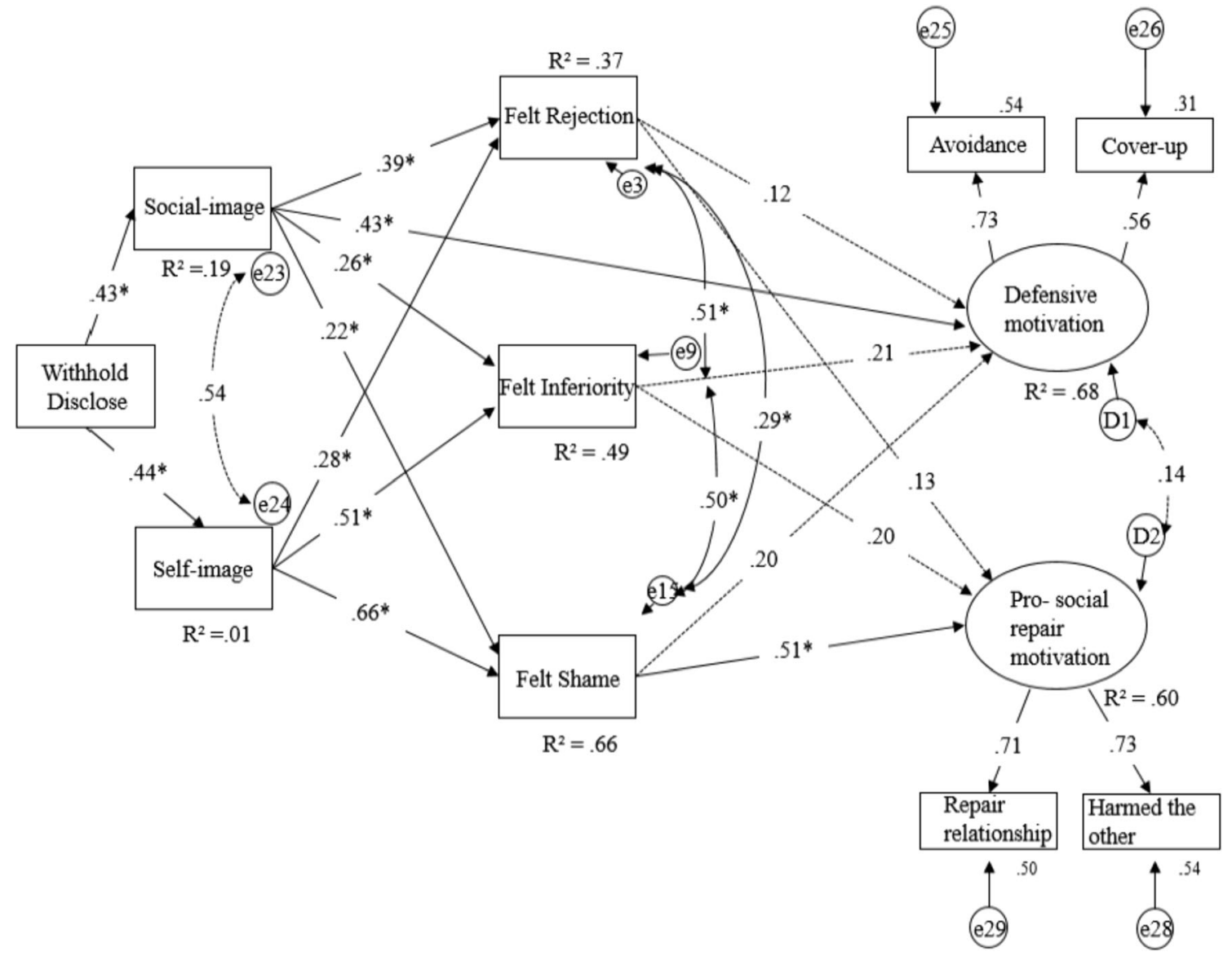

Fig. 2 Study 2. Structural model of the experimental effects on appraisals and feelings, and its relationship with the motivations. Dashed lines $>.05$ and solid lines $<.05$ 
unpleasant and distressing feelings are often hard to identify and even bypassed (Lewis, 1971; Scheff, 2000). We do acknowledge that it is difficult to fully assess all aspects of an emotional experience, especially the self-critical ones, and that self-report measures have their limitations, even as other methods (e.g., physiological reactions) also are subject to ambiguous interpretations. We believe future research should try to develop tools to tap into these understudied aspects of the emotional experience, triangulating with self-reports.

The third limitation is the characteristic of the sample in terms of age. Even though the age-range among our university participants spanned from 18 to the late $40 \mathrm{~s}$, most were still young adults (Mage $=24$ in Study 1, and 23 in Study 2). From a developmental perspective, some might say that a preponderance of young adults in our sample might influence results in terms of the appraisal of social-image, that is, that young people are more concerned about it and thus care more what others might think of them. However, social image is a concern for all ages; young and old, as there is little change in social and emotional functioning throughout life (Charles \& Carstensen, 2010). As such, the need to socially present oneself to others stays stable throughout the whole lifespan (Baumeister \& Leary, 1995). Mirroring this, we find it helpful to reflect over the fact that the appraisal of one's social-image in the eyes of others is a situation-specific appraisal that operates within the general formation of one's emotion experience, regardless of younger or older age (Gausel \& Leach, 2011; Lazarus, 1991). If there is any difference between ages, then it is that younger adults seem to focus more on presenting themselves socially to multiple people than do older adults. That is, there is ample evidence that older people are typically pickier about whom they should direct their social motivation (for a review, see Carstensen 1991; Charles \& Carstensen, 2010). But in our studies, the scenarios focused on a single other person, thus were relevant to older as well as younger people's self-presentation concerns.

\section{Thoughts on Culture}

Our data collection was conducted in a western, NorthEuropean culture where the norm leans toward being completely honest and 'objective' about information sharing, regardless of whether it hurts the other or not (Ma et al., 2011; Weil et al., 1994). This might not be similar to other cultures where it is seen as normatively correct to withhold the displeasing information in order to protect the other (e.g. a patient) from hurtful information (Muñoz Sastre et al., 2014; O'Sullivan, 2009), such as in Mediterranean countries where medical professionals tend to withhold unpleasant information from patients and rather share it with the family (Costantini et al., 2009). According to Weil et al. (1994) one can therefore assume that withholding information is valued more positively in collectivistic cultures than in individualistic cultures (see also Salem et al., 2013).

In a review, Sheikh (2014) found that individuals in collectivistic cultures reported more social-image related shame tendencies, than those in individualistic cultures. Nevertheless, it is clear that norms surrounding information sharing are relevant to social relationships across all cultures (Baile et al., 2000). As such, the Gausel and Leach (2011) model is more culturally flexible than most models on norm failures and shame-related emotions as it allows for the expressions of social-image concerns typically expressed in collectivistic cultures and the expressions of self-image concerns often expressed in individualistic cultures. For instance, the model has been applied in the African country of Liberia to investigate the role of social-image and shame in relation to the desire for reconciliation and the desire for revenge in the aftermath of the civil-wars (Gausel et al., 2018). Taken together, there is reason to expect cultural differences in how to respond to norm failures and which emotions and motivations should be expected. All the same, we should be open to the possibility that the parameters of this process model might be different in cultures that are more interconnected (but see Vignoles et al., 2016).

\section{Concluding Remarks}

Our results argue that, within the western, North-European cultural context, and for the type of situations envisioned, the least psychologically harmful thing to do for oneself if one gets to find out displeasing information about another is to disclose it. It will make the discloser experience less unpleasant appraisals and self-critical feelings, and there will therefore be less of a need to be defensive or repair the damaged relationship after the fact. Our findings further show that by thinking about the fault as a failure to meet self-image standards, instead of social-image standards, a 'transgressor' increases the chances of being motivated to pro-socially approach, repair, and strengthen the relationship, instead of defensively to withdraw, hide, and postpone any improvement in relations.

The data that support the findings of this study are available from the corresponding author, upon reasonable request.

Funding Open access funding provided by Ostfold University College.

Open Access This article is licensed under a Creative Commons Attribution 4.0 International License, which permits use, sharing, adaptation, distribution and reproduction in any medium or format, as long as you give appropriate credit to the original author(s) and the source, provide a link to the Creative Commons licence, and indicate if changes were made. The images or other third party material in this article are included in the article's Creative Commons licence, unless indicated otherwise in a credit line to the material. If material is not included in the article's 
Creative Commons licence and your intended use is not permitted by statutory regulation or exceeds the permitted use, you will need to obtain permission directly from the copyright holder. To view a copy of this licence, visit http://creativecommons.org/licenses/by/4.0/.

\section{References}

Alexander, C., \& Becker, H. (1978). The Use of Vignettes in Survey Research. The Public Opinion Quarterly, 42(1), 93-104. Retrieved April 10, 2021, from http://www.jstor.org/stable/2748094.

Back, A. L., Arnold, R. M., Baile, W. F., Tulsky, J. A., \& Fryer-Edwards, K. (2005). Approaching difficult communication tasks in oncology. CA: a Cancer Journal for Clinicians, 55(3), 164-177. https://doi. org/10.3322/canjclin.55.3.164

Baile, W. F., Buckman, R., Lenzi, R., Glober, G., Beale, E. A., \& Kudelka, A. P. (2000). SPIKES- A six step protocol for delivering bad news: Application to the patient with cancer. The Oncologist, 5 , 302-311. https://doi.org/10.1634/theoncologist.5-4-302.

Batson, C. D., Thompson, E. R., Seuferling, G., Whitney, H., \& Strongman, J. A. (1999). Moral hypocrisy: Appearing moral oneself without being so. Journal of Personality and Social Psychology, 77, 525-537. https://doi.org/10.1037/0022-3514.77.3.525.

Baumeister, R. F., \& Leary, M. R. (1995). The need to belong: Desire for interpersonal attachments as a fundamental human motivation. Psychological Bulletin, 117, 497-529. https://doi.org/10.1037/ 0033-2909.117.3.497.

Baxter, L. A. (1982). Strategies for ending relationships: Two studies. Western Journal of Speech Communication, 46, 223-241. https:// doi.org/10.1080/10570318209374082.

Berndsen, M., \& Gausel, N. (2015). When majority members exclude ethnic minorities: The impact of shame on the desire to object to immoral acts. European Journal of Social Psychology., 45, 728741. https://doi.org/10.1002/ejsp.2127.

Berndsen, M., \& McGarty, C. (2012). Perspective taking and opinions about forms of reparation for victims of historical harm. Personality and Social Psychology Bulletin, 38, 1316-1328. https://doi.org/10. 1177/0146167212450322.

Brambilla, M., \& Leach, C. W. (2014). On the importance of being moral: The distinctive role of morality in social judgement. Social Cognition, 32(4), 397-408. https://doi.org/10.1521/soco.2014.32. 4.397.

Brewin, T. B. (1991). Three ways of giving bad news. The Lancet, 337(8751), 1207-1209. https://doi.org/10.1016/0140-6736(91) 92870-8.

Cantarero, K., Byrka, K., Kosiarczyk, A., \& Dolinski, D. (2019). When the truth is painful. Perceived harm in truth telling affects choosing prosocial lying over truth telling. Unpublished manuscript, SWPD School of Social Sciences, https://doi.org/10.31234/osf.io/jm7y4.

Carstensen, L. L. (1991). Selectivity theory: Social activity in life-span context. Annual Review of Gerontology and Geriatrics, 11(1), 195217.

Charles, S. T., \& Carstensen, L. L. (2010). Social and emotional aging. Annual Review of Psychology, 61, 383-409.

Clark, M., \& Brisette, I. (2000). Relationship beliefs and emotion: Reciprocal effects. Cambridge University Press.

Cohen, J., Cohen, P., West, S., \& Aiken, L. (2003). Applied multiple regression/correlation analysis for the behavioral sciences (3rd edition). Lawrence Erlbaum Associates, Publisher.

Costantini, A., Baile, W. F., Lenzi, R., Costantini, M., Ziparo, V., Marchetti, P., \& Grassi, L. (2009). Overcoming cultural barriers to giving bad news: Feasibility of training to promote truth-telling to cancer patients. Journal of Cancer Education, 24(3), 180-185.
Fearon, D. S. Jr j. (2004). The bond threat sequence. In L. Tiedens \& C. Leach (Eds.), The social life of emotions. Cambridge, UK: Cambridge University Press.

Filho, B., Silva, A., \& Rocha, E. (2011). What is R2 all about? LeviathanCadernos de Pesquisa Politica, 3, 60-68. https://doi.org/10.11606/ issn.2237-4485.lev.2011.132282.

Gausel, N. (2013). Self-reform or self-defense? Understanding why people cope with their moral failures by understanding how they appraise and feel about their moral failures. In M. Moshe \& N. Corbu (Eds.), Walk of shame (pp. 191-208). Nova Publishers.

Gausel, N., \& Brown, R. (2012). Shame and guilt - do they really differ in their focus of evaluation? Wanting to change the self and behavior in response to ingroup immorality. Journal of Social Psychology, 152, 547-567. https://doi.org/10.1080/00224545.2012.657265.

Gausel, N., \& Leach, C. (2011). Concern for self-image and social image in the management of moral failure: Rethinking shame. European Journal of Social Psychology, 41, 468-478. https://doi.org/10.1002/ ejsp.803.

Gausel, N., Leach, C., Vignoles, V., \& Brown, R. (2012). Defend or repair? Explaining responses to in-group moral failure by disentangling feelings of shame, rejection, and inferiority. Journal of Personality and Social Psychology, 102, 941-960. https://doi. org/10.1037/a0027233.

Gausel, N., Vignoles, V. L., \& Leach, C. W. (2016). Resolving the paradox of shame: Differentiating among specific appraisal-feeling combinations explain pro-social and self-defensive motivation. Motivation and Emotion, 40, 118-139. https://doi.org/10.1007/ s11031-015-9513-y.

Gausel, N., Leach, C. W., Mazziotta, A., \& Feuchte, F. (2018). Seeking revenge or seeking reconciliation? How concern for social-image and felt shame helps explain responses in reciprocal intergroup conflict. European Journal of Social Psychology, 48, 62-72. https://doi. org/10.1002/ejsp.2295.

de Hooge, I. E., Nelissen, R. M. A., Breugelmans, S. M., \& Zeelenberg, M. (2011). What is moral about guilt? Acting "prosocially" at the disadvantage of others. Journal of Personality and Social Psychology, 100(3), 462-473. https://doi.org/10.1037/a0021459.

Iyer, A., Schmader, T., \& Lickel, B. (2007). Why individuals protest the perceived transgressions of their country: The role of anger, shame, and guilt. Personality and Social Psychology Bulletin, 33, 572-587. https://doi.org/10.1177/0146167206297402.

Jeffries, H. C., \& Hornsey, M. (2012). Withholding negative feedback: Is it about protecting the self or protecting others? British Journal of Social Psychology, 51(3), 772-780. https://doi.org/10.1111/j.20448309.201.02098.x.

Kenny, D. A., Kaniskan, B., \& McCoach, D. B. (2015). The performance of RMSEA in models with small degrees of freedom. Sociological Methods \& Research, 44(3), 486-507. https://doi.org/10.1177/ 0049124114543236.

Kline, R. B. (2011). Principles and practice of structural equation modeling (3rd ed., p. XVI, 427 ill.). Guilford Press.

Lazarus, R. S. (1991). Emotion \& adaption. Oxford University Press.

Leach, C. W., \& Cidam, A. (2015). When shame is linked to constructive approach orientation? Journal of Personality and Social Psychology, 109(983-1002), 983-1002. https://doi.org/10.1037/ psps0000037983.

Leach, C. W., Bilali, R., \& Pagliaro, S. (2015). Groups and morality. In M. Mikulincer, P. R. Shaver, J. F. Dovidio, \& J. Simpson (Eds.), APA handbook of personality and social psychology (Group processes) (Vol. 2, pp. 123-149). American Psychological Association.

Levine, E., \& Cowan, N. (2018). You can handle the truth: Mispredicting the consequences of honest communication. Journal of Experimental Psychology: General, 147(9), 1400-1429. https:// doi.org/10.1037/xge0000488. 
Levine, E. E., \& Schweitzer, M. E. (2014). Are liars ethical? On the tension between benevolence and honesty. Journal of Experimental Social Psychology, 53, 107-117.

Lewis, H. B. (1971). Shame and guilt in neurosis. International Universities Press.

Lezzoni, L., Rao, S., DesRoches, C., Vogeli, C., \& Campbell, E. (2012). Survey shows that at least some physicians are not always open or honest with patient. Health Affairs, 31(2), 383-391. https://doi.org/ 10.1377/hlthaff.2010.1137.

Lickel, B., Schmader, T., Curtis, M., Scarnier, M., \& Ames, D. R. (2005). Vicarious shame and guilt. Group Processes and Intergroup Relations, 8, 145-157. https://doi.org/10.1177/1368430205051064.

Lickel, B., Kushlev, K., Savalei, V., Matta, S., Schmader, T., \& Desteno, D. (2014). Shame and the motivation to change the self. Emotion, 14(6), 1049-1061. https://doi.org/10.1037/a0038235.

Ma, F., Xu, F., Heyman, G. D., \& Lee, K. (2011). Chinese children's evaluations of white lies: Weighing the consequences for recipients. Journal of Experimental Child Psychology, 108, 308-321. https:// doi.org/10.1016/j.jecp.2010.08.015.

Muñoz Sastre, M. T., Sorum, P. C., \& Mullet, E. (2014). Lay people's and health professionals' views about breaking bad news to children. Child: Care, Health \& Development, 40(1), 106-114. https://doi. org/10.1111/j.1365-2214.2012.01420.x.

O'Sullivan, E. (2009). Withholding truth from patients. (Art \& science: Ethical issues)(report). Nursing Standard, 23(48), 35-40.

Pardede, S., Gausel, N., \& Høie, M. M. (2021). Revisiting the "the breakfast club": Testing different theoretical models of belongingness and acceptance (and social self-representation). Frontiers in Psychology, 11, 604090. https://doi.org/10.3389/fpsyg.2020.604090.

Robinson, M., \& Clore, G. (2001). Simulation, scenarios, and emotional appraisal: Testing the convergence of real and imagined reactions to emotional stimuli. Personality and Social Psychology Bulletin, 27(11), 1520-1532. https://doi.org/10.1177/01461672012711012.

Rogers, C. R. (1961). On becoming a person. Houghton Mifflin Company.

Salem, A., \& Salem, A. F. (2013). Breaking bad news: Current prospective and practical guideline for Muslim countries. Journal of Cancer Education, 28(4), 790-794.
Scheff, T. (1994). Microsociology: Discourse, emotion, and social structure. University of Chicago Press.

Scheff, T. (2000). Shame and the social bond: A sociological theory. Sociological Theory, 18(1), 84-99. https://doi.org/10.1111/07352751.00089 .

Sheikh, S. (2014) Cultural variations in shame's responses. Personality and Social Psychology Review ,18(4), 387-403.

Shepherd, L., Spears, R., \& Manstead, A. S. (2013). The self-regulatory role of anticipated group-based shame and guilt in inhibiting ingroup favoritism. European Journal of Social Psychology, 43(6), 493. https://doi.org/10.1002/ejsp.1971.

Sparks, L., Villagran, M. M., Parker-Raley, J., \& Cunningham, C. B. (2007). A patient-centered repair to breaking bad news: Communication guidelines for health care providers. Journal of Applied Communication Research, 35(2), 177-196. https://doi.org/ 10.1080/00909880701262997.

Tangney, \& Dearing, R. L. (2002). Shame and guilt. Guildford.

Tangney, Miller, R. S., Flicker, L., \& Barlow, D. H. (1996). Are shame, guilt, and embarrassment distinct emotions? Journal of Personality \& Social Psychology, 70(6), 1256-1269.

Tangney, Stuewig, A., \& Martinez, G. (2014). Two faces of shame: The roles of shame and guilt in predicting recidivism. Psychological Science, 25(3), 799-805. https://doi.org/10.1177/0956797613508790.

Vignoles, V. L., Owe, E., Becker, M., Smith, P. B., Easterbrook, M. J., Brown, R., et al. (2016). Beyond the 'East-West' dichotomy: Global variation in cultural models of selfhood. Journal of Experimental Psychology: General, 145, 966-1000. https://doi.org/10.1037/ xge0000175.

Weil, M., Smith, M., \& Khayat, D. (1994). Truth-telling to cancer patients in the western European context. Psycho-Oncology, 3(1), $21-$ 26. https://doi.org/10.1002/pon.2960030105.

Publisher's Note Springer Nature remains neutral with regard to jurisdictional claims in published maps and institutional affiliations. 